\title{
Die Makkabäer
}

Hrsg. v. Friedrich Avemarie, Predrag Bukovec, Stefan Krauter u. Michael Tilly, unter Mitarb. v. Hendrik Stoppel

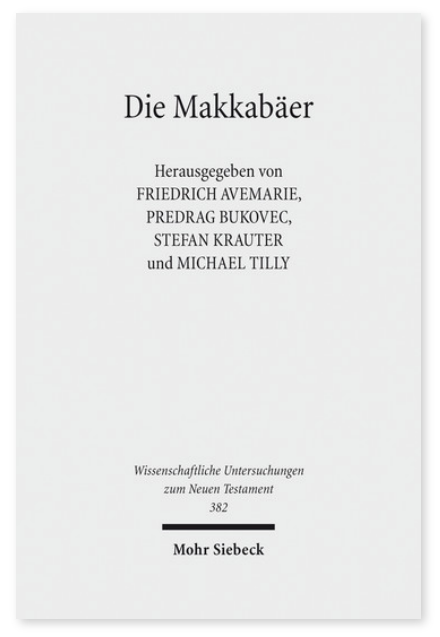

2017. XI, 471 Seiten. WUNT I 382

ISBN 978-3-16-155252-6

DOI 10.1628/978-3-16-155252-6

eBook PDF 209,00€

ISBN 978-3-16-153861-2

Leinen $209,00 €$
Für die formative Phase sowohl des antiken Judentums als auch des frühen Christentums stellt die Makkabäerzeit in vielerlei Hinsicht eine Referenzgröße dar. Neben der politischen Bedeutung, die ein eigenständiger jüdischer Staat im Zeitalter des Hellenismus besaß, sind als solche paradigmatische Entwicklungen das komplexe Ineinander von Ethnos und Bekenntnis im Judentum, die Durchsetzung der Tora und der Bibel als verbindliche Textcorpora oder die Herausbildung religiöser Institutionen und Parteien zu nennen. Im Bereich der Theologie wirkten die Diskurse der Makkabäerzeit entscheidend auf die jüdische und christliche Eschatologie, Martyrologie und Soteriologie ein.

Der vorliegende Band versucht erstmalig eine Gesamtschau dieser Epoche in mehrdimensionaler Sicht: In thematisch ausgerichteten, interdisziplinären Gruppen befassen sich ausgewiesene Expertinnen und Experten sowohl synchron mit der Zeitgeschichte und Literatur als auch diachron mit der weitreichenden Rezeption der Makkabäerbücher und ihrer Zeit.

\section{Inhaltsübersicht}

Achim Lichtenberger: Die Jerusalemer Religionsreform im Kontext. Antiochos IV., Antiochia und Zeus Olympios - Hermann Lichtenberger: Die Qumrantexte als Quelle für die Makkabäerzeit - Anders Klostergaard Petersen: 1 Maccabees from an Axial Age Perspective - Daniel R. Schwartz: 1 Maccabees 14 and the History of the Hasmonean State - Jan Willem van Henten: Time as a Narrative Tool in 2 Maccabees - Beate Ego: Der Tempel im 2. Makkabäerbuch im Kontext der Jerusalemer Kultkonzeption - Clemens Leonhard: Tempelfeste außerhalb des Jerusalemer Tempels in der Diaspora - Markus Öhler: Judäer oder Juden? Die Debatte »Ethnos vs. Religion« im Blick auf das 2. Makkabäerbuch - Luke Neubert: Inventing Jason of Cyrene? 2 Maccabees and the Epitome - Armin Lange: Jeremia in den Makkabäerbüchern - Johannes Bernhardt: Das Bild der Hasmonäerfamilie in den Makkabäerbüchern - Anna Maria Schwemer: Zu Entstehungszeit und -ort des 4. Makkabäerbuchs Predrag Bukovec: Per aspera ad astra. Leben nach dem Tod im 4. Makkabäerbuch - Jan Dochhorn: »lch bewahrte die gebaute Seite« (4 Makk 18,7). Eine Referenz auf die Verführung der ersten Frau im vierten Makkabäerbuch und ihre überlieferungsgeschichtlichen Hintergründe - Stefan Krauter: Tacitus über Antiochos IV. und die Makkabäer - Gerbern S. Oegema: 1 and 2 Maccabees in Paul's Letter to the Galatians - Dieter Richter: Die Geschichte vom Martyrium der Sieben Brüder (2 Makk 7) in der westlichen Tradition - Matthias Morgenstern: »Gendered Resistance«. Anmerkungen zur MakkabäerRezeption im rabbinischen und modernen Judentum - Hans P. Lichtenberger: Judentum und Griechentum bei Hermann Cohen - Thomas Knöppler: Marksteine der wissenschaftlichen Arbeit am 3. Makkabäerbuch (1564 - 1913)

Friedrich Avemarie (1960-2012) Studium der Ev. Theologie in Heidelberg, München, Montpellier und Tübingen; Studium der Judaistik in Jerusalem und Berlin; 1995 Promotion; 2000 Habilitation; 2002-12 Professor für Neues Testament und antikes Judentum in Marburg.

Predrag Bukovec Geboren 1986; 2005-10 Studium der Kath. Theologie und der Sprachen und Kulturen des Christlichen Orients (M.A.) an der Universität Tübingen; 2017 Promotion (Dr. theol.) und 2019 Promotion (PhD), Universität Wien; seit 2020 Assistenz-Professor für Liturgiewissenschaft und Sakramententheologie, Katholische Privat-Universität Linz, Fakultät für Theologie; seit 2021 Projektleiter des DFG-Projekts »Zu den Ursprüngen der Taufsalbung«, Universität Regensburg. https://orcid.org/0000-0002-1321-5874

Stefan Krauter Geboren 1973; Studium der Ev. Theologie und lateinischen Philologie; 2004 Promotion; 2009 Habilitation; 2009-19 Pfarrer der Ev. Münstergemeinde Ulm; seit 2019 Assistenzprofessor für Neues Testament an der Theologischen Fakultät der Universität Zürich.

https://orcid.org/0000-0002-4932-9224

Michael Tilly Geboren 1963; Studium der Ev. Theologie in Mainz und Heidelberg; 1993 Promotion und 2001 Habilitation an der Johannes Gutenberg-Universität Mainz; Professor für Neues Testament an der Eberhard Karls Universität Tübingen. https://orcid.org/0000-0002-7217-3782

Hendrik Stoppel ist Wissenschaftlicher Mitarbeiter an der Forschungsstätte der Evangelischen Studiengemeinschaft in Heidelberg.

https://orcid.org/0000-0002-7404-1679

Jetzt bestellen:

https://mohrsiebeck.com/buch/die-makkabaeer-9783161552526?no_cache=1

order@mohrsiebeck.com

Telefon: +49 (0)7071-923-17

Telefax: $+49(0) 7071-51104$ 